\title{
Fatigue strength of several dental ceramics indicated for CAD-CAM monolithic restorations
}

\author{
Gabriela NISHIOKA(a) \\ Catina PROCHNOW(b) \\ Aline FIRMINO(a) \\ Marina AMARAL(c) \\ Marco Antonio BOTTINO(a) \\ Luiz Felipe VALANDRO(b) \\ Renata Marques de MELO(a)
}

(a) Universidade Estadual Paulisa - Unesp,

Faculty of Odontology, Department of Dental Materials and Prosthodontics, São José dos Campos, SP, Brazil.

(b) Universidade Federal de Santa Maria UFSM, Faculty of Odontology, Department of Restorative Dentistry, Santa Maria, RS, Brazil.

(c) Universidade de Taubaté - Unitau, Faculty of Dentistry, Post-Graduate Program in Dentistry, Taubaté, São Paulo State, Brazil.

Declaration of Interests: The authors certify that they have no commercial or associative interest that represents a conflict of interest in connection with the manuscript.

Corresponding Author:

Luiz Felipe Valandro

E-mail: Ifvalandro@hotmail.com

hitps://doi.org/10.1590/1807-3107bor-2018.vol32.0053

Submitted: January 22, 2018

Accepted for publication: April 16, 2018

Last revision: May 04, 2018

\begin{abstract}
This in vitro study evaluated the fatigue strength of different ceramic materials indicated for monolithic restorations. Disc-shaped specimens were made according to ISO 6872 from five different ceramic materials: feldspathic ceramic (FC), polymer-infiltrated ceramic network (PIC), lithium disilicate glass-ceramic (LD), zirconia-reinforced lithium silicate glass-ceramic (ZLS), and high translucent tetragonal zirconia polycrystals doped by yttrium (YZ-HT). After obtaining the mean of each material $(n=5)$ from monotonic load-to-failure tests, specimens $(n=20)$ were subjected to fatigue tests (staircase method) using a biaxial flexural setup (piston-on-three-balls), to determine the fatigue strength. The parameters used for fatigue tests were: 100,000 cycles at $10 \mathrm{~Hz}$, initial load of $\sim 60 \%$ of mean load-to-failure, and step size of $5 \%$ of the initial load (specific for each ceramic material). Kruskal-Wallis and Bonferroni's test $(\alpha=0.05)$ were used to analyze the fatigue strength data. Fatigue strength (MPa) of the materials was statistically different among each other as follows: YZ-HT (370.2 \pm 38.7$)>$ LD (175.2 \pm 7.5$)>$ ZLS (152.1 \pm 7.5$)>$ PIC (81.8 $\pm 3.9)>$ FC $(50.8 \pm 1.9)$. Thus, it can be concluded that, in terms of fatigue, high translucent polycrystalline zirconia is the best choice for monolithic restorations as it bears the highest load before cracking/fracturing.
\end{abstract}

Keywords: Ceramics; Computer-Aided Design; Dental Materials; Dental Porcelain.

\section{Introduction}

Over the last decades, a shift toward metal-free restorations has been observed in dentistry. To meet the increased demands of patients and dentists in terms of esthetics, biocompatibility, and long-term survival of the restorations, several types of all-ceramic systems have been developed, from glass ceramics to zirconia polycrystal materials. ${ }^{1,2}$

The main intent of the industry is to refine the composition and microstructure of the ceramic materials to produce a tougher ceramic without compromising esthetics. ${ }^{3}$ The lithium disilicate IPS e.Max (Ivoclar Vivadent) falls into this category, having strong needle-like crystals embedded within a glassy matrix ${ }^{4}$ that mimics the appearance of enamel and works well for crown applications. ${ }^{5,6}$ Among the newer ceramics, the materials based on lithium silicate reinforced by zirconium oxide (such as Suprinity, Vita Zahnfabrik, Bad Sackingen, Germany; Celtra Duo CAD, 
Degudent GmbH, Hanau; Wolfgang, Germany) and glass-ceramic infiltrated by polymer, also known as hybrid ceramic, should be mentioned (such as Enamic, Vita Zahnfabrik). ${ }^{2}$ Although highly esthetic, these ceramic materials are rich in silica content and are not as strong as materials based on dense zirconia polycrystals; hence, they are less suitable when high stress concentrations must be endured.? Vita YZ HT (Vita Zahnfabrik) is a ceramic based on yttrium-stabilized tetragonal zirconia polycrystals (Y-TZP), which is microstructurally different from its predecessor material (Vita In-Ceram YZ). The changes ensure greater translucency compared with opaque zirconia materials used for frameworks, in addition to the higher mechanical properties. ${ }^{8,9}$ In general, all of the aforementioned materials have been indicated for all-ceramic monolithic restorations, and are available as pre-fabricated blocks for CAD-CAM (computer-aided design/computer-aided manufacturing) systems.

The bilayer system (zirconia + glass-ceramic veneering material) is susceptible to chipping, and the cracks usually initiate at the interface between the ceramic core and the veneer. ${ }^{10}$ In addition, other drawbacks are the weak bonding between the core and the veneer and/or the residual tensile stress developed during the process of veneering. ${ }^{11}$ Thus, monolithic crowns have been indicated mainly to prevent this type of failures and have shown improvements in performance and esthetics (due to excellent optical properties). ${ }^{12,13}$

Aiming to reproduce the clinical condition (presence of moisture and mechanical loading) and predict the mechanical behavior, restorative materials have been subjected to laboratorial fatigue tests by the application of cyclic loads. ${ }^{14}$ Dental ceramics with different compositions, microstructures, and properties might behave differently when exposed to fatigue loading. Thus, to better understand their susceptibility to crack propagation under intermittent loading, it is relevant to compare the fatigue strength (fatigue behavior) of novel ceramic materials indicated for monolithic restorations.

Therefore, the aim of the present study was to evaluate the biaxial flexural fatigue behavior by the staircase method of feldspathic ceramic, polymer-infiltrated ceramic network, zirconia-reinforced lithium silicate glass-ceramic, lithium disilicate glass-ceramic, and yttrium partially stabilized tetragonal zirconia polycrystals. The hypothesis tested was that the materials (i.e., with distinct compositions) present different fatigue strength results.

\section{Methodology}

The information about the ceramic materials used in this study is described in Table 1.

\section{Specimens Preparation}

Disc-shaped specimens $(\mathrm{n}=25 ; 5$ for biaxial monotonic load-to-failure test and 20 for biaxial fatigue strength test) of five different ceramic materials (Table 1) were produced according to ISO $6872 .{ }^{15}$ The ceramic blocks were water-ground into cylinders in a polishing machine (EcoMet/AutoMet 250, Buehler; Lake Bluff, EUA) with a \#400 grit silicon carbide paper

Table 1. Materials used in this study.

\begin{tabular}{|c|c|c|c|c|c|}
\hline Material & Commercial brand & Manufacturer & Main composition & $\begin{array}{l}\text { Batch } \\
\text { number }\end{array}$ & $\begin{array}{l}\text { Poisson's } \\
\text { ratio }\end{array}$ \\
\hline Feldspathic ceramic (FC) & VITABLOCS Mark II & Vita Zahnfabrik & $\begin{array}{c}\mathrm{SiO}_{2}, \mathrm{Al}_{2} \mathrm{O}_{3}, \mathrm{Na}_{2} \mathrm{O}, \mathrm{K}_{2} \mathrm{O} \\
\mathrm{CaO}, \mathrm{TiO}_{2}\end{array}$ & 36710 & $0.23^{a}$ \\
\hline Polymer-infiltrated ceramic network (PIC) & VITA Enamic & Vita Zahnfabrik & $\begin{array}{c}\mathrm{SiO}_{2}, \mathrm{Al}_{2} \mathrm{O}_{3}, \mathrm{Na}_{2} \mathrm{O}, \mathrm{K}_{2} \mathrm{O} \\
\mathrm{B}_{2} \mathrm{O}_{3}, \mathrm{Zr}_{2} \mathrm{O}, \mathrm{CaO}\end{array}$ & 48040 & $0.23^{b}$ \\
\hline $\begin{array}{l}\text { Zirconia-reinforced lithium silicate } \\
\text { glass-ceramic (ZLS) }\end{array}$ & VITA Suprinity & Vita Zahnfabrik & $\begin{array}{c}\mathrm{SiO}_{2}, \mathrm{Li}_{2} \mathrm{O}, \mathrm{K}_{2} \mathrm{O}, \mathrm{P}_{2} \mathrm{O}_{5} \\
\mathrm{Al}_{2} \mathrm{O}_{3}, \mathrm{ZrO}_{2}, \mathrm{CeO}_{2}\end{array}$ & 48150 & $0.23^{a}$ \\
\hline Lithium disilicate glass-ceramic (LD) & IPS e.Max CAD & Ivoclar Vivadent & $\begin{array}{l}\mathrm{SiO}_{2} . \mathrm{Li}_{2} \mathrm{O}, \mathrm{K}_{2} \mathrm{O}, \mathrm{MgO} \\
\mathrm{Al}_{2} \mathrm{O}_{3}, \mathrm{P}_{2} \mathrm{O}_{5}, \mathrm{ZrO}_{2}, \mathrm{ZnO}_{2}\end{array}$ & P84146 & $0.22^{a}$ \\
\hline $\begin{array}{l}\text { High translucent yttrium partially stabilized } \\
\text { tetragonal zirconia polycrystals (YZ-HT) }\end{array}$ & Zirconia YZ HT & Vita Zahnfabrik & $\begin{array}{c}\mathrm{ZrO}_{2}, \mathrm{Y}_{2} \mathrm{O}_{3}, \mathrm{Al}_{2} \mathrm{O}_{3}, \mathrm{SiO}_{2} \\
\mathrm{Fe}_{2} \mathrm{O}_{3}, \mathrm{Na}_{2} \mathrm{O}\end{array}$ & 48980 & $0.32^{c}$ \\
\hline
\end{tabular}


(3M, St Paul, USA), and cut (Isomet 1000, Buehler) with a diamond saw under water cooling to produce disc-shaped specimens.

The discs were polished down using a series of silicon carbide papers (3M) of decreasing grit size (\#60, \#120, \#400, \#600, and \#1200 - 30 seconds per grit paper). After, the samples were cleaned in an ultrasonic bath (Vitasonic, Vita, Bad Sackingen, Germany) with isopropyl alcohol for $5 \mathrm{~min}$.

The ZLS and LD discs were crystallized (Vita Vacumat 6000MP; Vita), and the YZ-HT discs were sintered (Vita Zyrcomat; Vita), as recommended by the manufacturer. The final dimensions of the specimens were $12 \mathrm{~mm}$ in diameter and $1.2 \pm 0.02 \mathrm{~mm}$ in thickness.

\section{Monotonic biaxial load-to-failure tests}

Five samples of each group were tested in a universal testing machine (EMIC DL-2000; São José dos Pinhais, Brazil) for monotonic biaxial flexural strength according to ISO $6872^{15}$ in a piston-on-three-ball setup under water, and flexural strength was calculated as previously described by Pereira et al. ${ }^{16}$ Poisson's ratios used for each ceramic material are described in Table 1, and based in previous studies. . $^{17,18,19}$

\section{Biaxial fatigue strength tests}

The biaxial fatigue strength was determined by the staircase approach $(100,000$ cycles at $10 \mathrm{~Hz})$ conducted in an electric machine (Instron Electro Puls E3000, Instron Corporation; Norwood, United States) using a piston-on-three-balls setup under water, also according to ISO $6872 .{ }^{15}$ The staircase method, originally described by Collins, ${ }^{20}$ has been used in several studies. ${ }^{21,22,23,24}$
To perform the staircase test, the number of cycles was previously set (100,000 cycles). The first specimen was tested at a stress level lower than the maximum stress supported by the materials in a corresponding static test $60 \%$ of mean monotonic load-to-failure test performed with the same assembly of the fatigue test, in MPa), until it either failed or survived at the predetermined cycles. A step size of approximately $5 \%$ of the initial stress level (in MPa) for each group was applied to the next specimen, either added or subtracted according to survival or failure, respectively. This procedure was repeated until at least 15 samples per group were evaluated after the first reversal, which, according to Collins,,$^{20}$ is the minimum number of specimens for a precise estimation using this approach. The staircase approach results in a stair-like graph according to the survival or failure of each specimen.

\section{Fractography}

The fractured specimens were observed under a light microscope to determine the failure origin (Discovery V20, Carl-Zeiss; Gottingen, Germany). Representative samples were further examined under a scanning electron microscope (up to $5000 \times$ magnification; Inspect S50, FEI Company; Brno, Czech Republic).

\section{Statistical Analysis}

After rejecting normality and homogeneity, fatigue strength values were submitted to Kruskal-Wallis and Bonferroni's post hoc test ( $\mathrm{a}=0.05)$, by SPSS statistics 24.0 .

\section{Results}

Table 2 presents the mean values obtained in monotonic biaxial flexural strength tests, which

Table 2. Mean biaxial flexural strength $(n=5)$, initial fatigue strength, step size, fatigue strength data (in MPa) after 100,000 cycles, and the percentage comparison between monotonic and fatigue strength results.

\begin{tabular}{lccccc}
\hline $\begin{array}{l}\text { Ceramic } \\
\text { material }\end{array}$ & $\begin{array}{c}\text { Mean biaxial flexural } \\
\text { strength }\end{array}$ & Initial fatigue strength & $\begin{array}{c}\text { Step size } \\
\text { increment }\end{array}$ & $\begin{array}{c}\text { Fatigue strength } \\
\text { (Mean } \pm \text { SD) }\end{array}$ & $\begin{array}{c}\text { Decrease from monotonic } \\
\text { strength to fatigue strength (\%) }\end{array}$ \\
\hline FC & $76.8 \mathrm{MPa}$ & $46.0 \mathrm{MPa}$ & $2 \mathrm{MPa}$ & $50.8 \pm 1.9^{\mathrm{E}}$ & 33.9 \\
$\mathrm{PIC}$ & $130.0 \mathrm{MPa}$ & $78.0 \mathrm{MPa}$ & $4 \mathrm{MPa}$ & $81.8 \pm 3.9^{\mathrm{D}}$ & 37.1 \\
ZLS & $240.0 \mathrm{MPa}$ & $144.0 \mathrm{MPa}$ & $7 \mathrm{MPa}$ & $152.1 \pm 7.5^{\mathrm{C}}$ & 36.6 \\
LD & $295.2 \mathrm{MPa}$ & $177.0 \mathrm{MPa}$ & $9 \mathrm{MPa}$ & $175.2 \pm 7.5^{\mathrm{B}}$ & 40.7 \\
YZ-HT & $635.0 \mathrm{MPa}$ & $445.0 \mathrm{MPa}$ & $22 \mathrm{MPa}$ & $370.2 \pm 38.7^{\mathrm{A}}$ & 41.7 \\
\hline
\end{tabular}

Different uppercase letters mean statistical difference. 
were used to determinate the initial strength and step increment for fatigue tests. YZ-HT presented the highest fatigue strength value and the lowest value

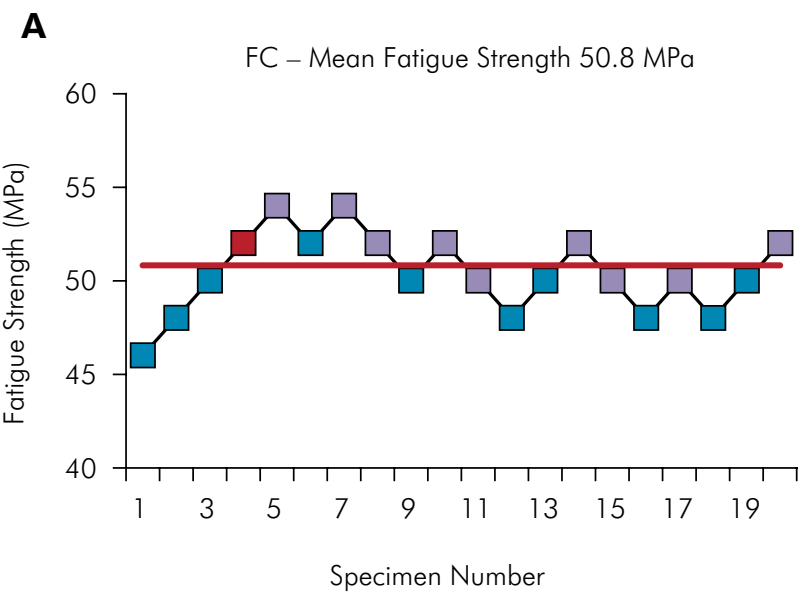

C

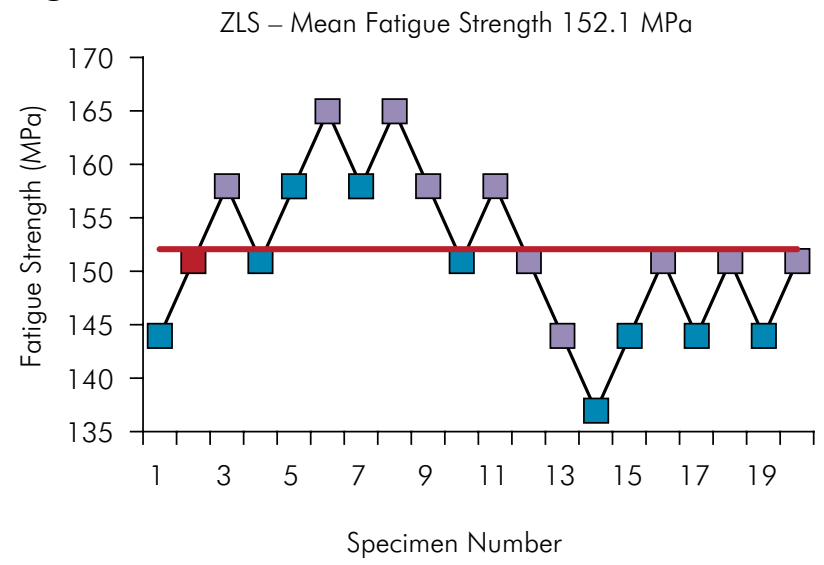

was presented by FC (Table 2). Figure 1 shows the graphs of the staircase approach: survived samples are represented by the blue shaded squares and

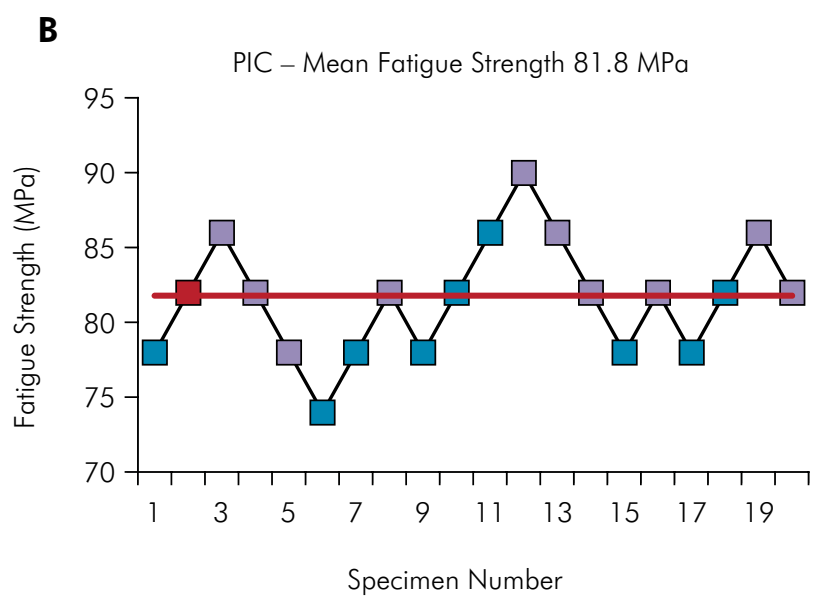

D

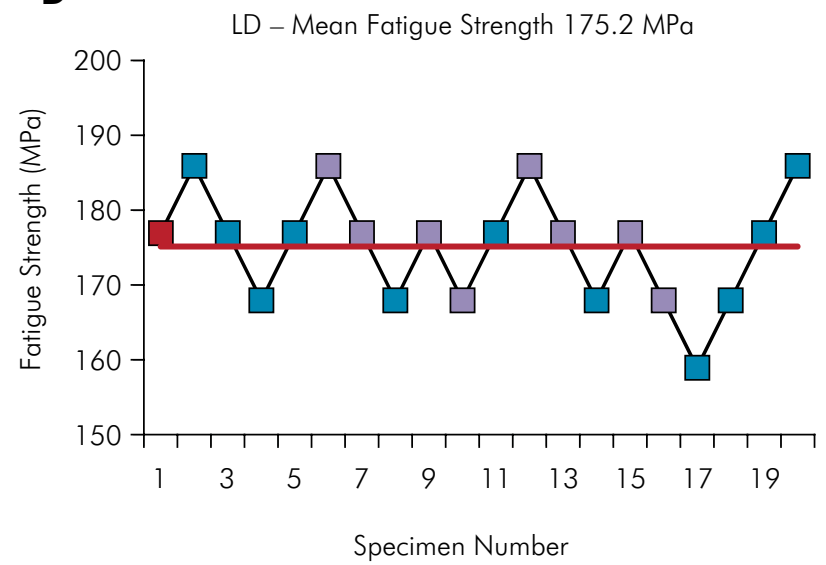

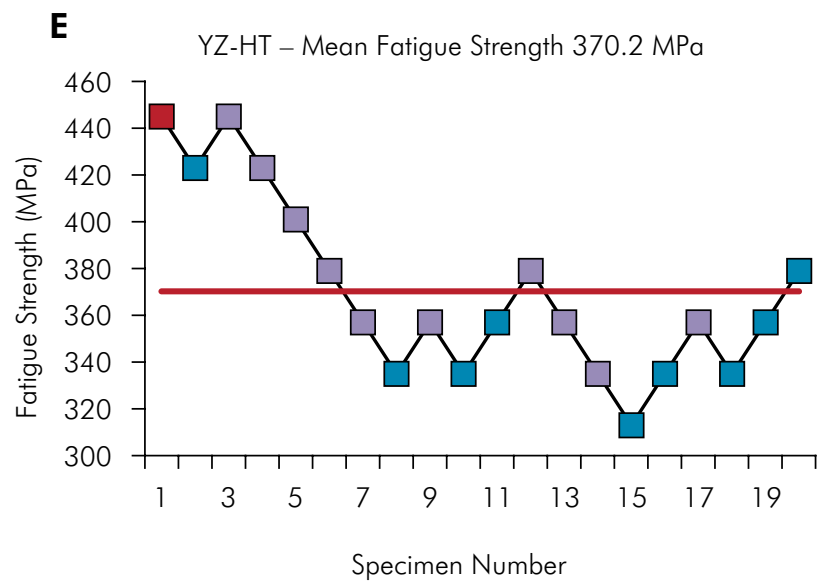

Figure 1. Staircase sensitive results after 100,000 cycles at $10 \mathrm{~Hz}$. The lines indicate the mean fatigue strength, the blue shaded elements indicate the surviving specimens, the purple indicate fractured specimens, and the red ones indicate the specimen on which the staircase initiated according to Collins. 

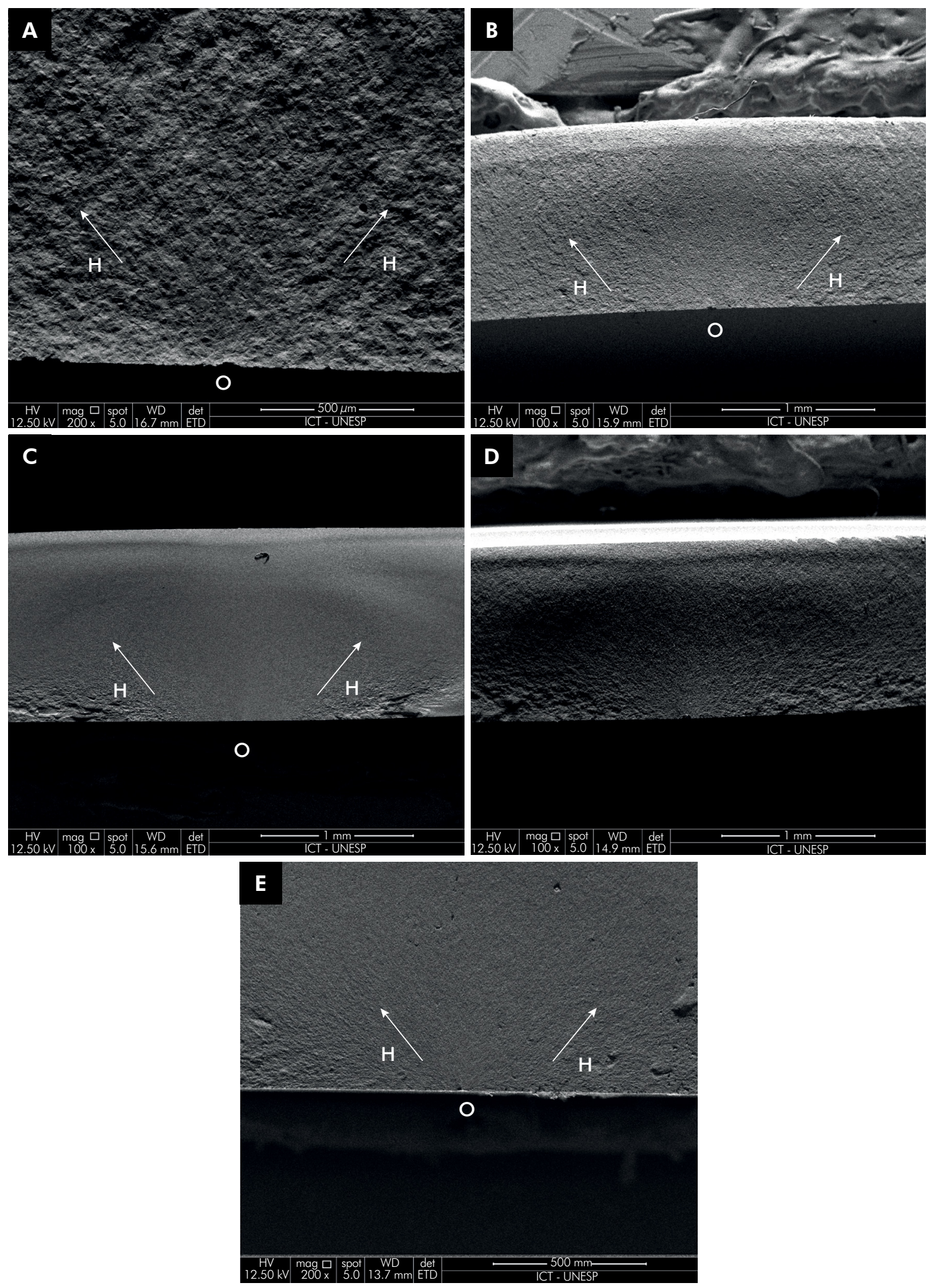

Figure 2. Representative scanning electron microscopy images of the fractured discs subjected to fatigue test: (A) feldspathic ceramic, (B) polymer-infiltrated ceramic network, (C) zirconia-reinforced lithium silicate glass-ceramic, (D) lithium disilicate glass-ceramic, and (E) yttrium partially stabilized tetragonal zirconia polycrystals. The arrows indicate the direction of crack propagation. The crack origins (O), mainly semi-elliptical flaws on the surface, and the surrounding hackle lines $(H)$ are also displayed. 
failed samples, by the purple shaded squares. The fractography showed that all the fractures initiated at the side of the disk under tensile stress, opposite to the load application site. Surface defects were the main origin of fractures.

\section{Discussion}

High translucence yttrium stabilized tetragonal zirconia polycrystals (YZ-HT) had the highest fatigue strength, followed by lithium disilicate glass-ceramic (LD), zirconia reinforced silicate glass-ceramic (ZLS), polymer-infiltrated ceramic network (PIC), and feldspathic materials (FC), in a decreasing order (Table 2). Thus, the tested hypothesis was accepted, since the ceramic materials for monolithic restorations with different microstructures resulted in different flexural fatigue strengths (Figure 1).

Our results are in agreement with previous studies, justifying the use of the $\mathrm{YZ}$ ceramic for restorations subjected to high stress concentration, such as posterior crowns and multi-unit fixed partial dentures. ${ }^{25,26}$ Baladhandayutham et al. ${ }^{26}$ achieved similar values when comparing fracture strength between monolithic crowns of lithium disilicate (1.2 and $1.5 \mathrm{~mm}$ thickness) and zirconia crowns of 0.6 $\mathrm{mm}$ thickness, demonstrating a significantly higher fracture strength for zirconia. Similarly, Johansson et al. ${ }^{25}$ reported higher fracture strength values for two highly translucent $\mathrm{YZ}$ materials compared to LD monolithic restorations.

The higher values for YZ-HT compared to the other tested materials were expected, since a phenomenon called transformation toughening takes place in dense tetragonal polycrystalline zirconia materials doped by yttrium when subjected to mechanical stimuli. The tetragonal zirconia phase transforms to the monoclinic phase, causing a local volume increase of approximately $4 \%,{ }^{27}$ increasing the material strength. This increase in volume counteracts crack propagation by causing compression at the tip of the crack.

The traditional zirconia lacks translucency, resulting in opaque restorations. The opacity is directly related to the increase in thickness. ${ }^{28,29}$ To enhance zirconia translucency, some strategies may be adopted, such as removing any alumina from the zirconia composition, increasing the amount of cubic phase, and reducing the grain size. ${ }^{29}$ These alterations lead to a more brittle, weaker material (provided by the addition of cubic phase) that is susceptible to low temperature degradation (due to removal of alumina), ${ }^{29}$ which may explain the lower strength results of the YZ-HT group, compared to previous literature. ${ }^{25,26}$

The materials composed of lithium crystals embedded in a glassy matrix (i.e., LD and ZLS materials) obtained intermediate fatigue strengths (lower than YZ-HT but higher than PIC and FC). Our results are not in agreement with those of Elsaka et al. ${ }^{7}$ as they found higher mechanical properties (flexural strength and fracture toughness) for ZLS compared to LD. Although the manufacturer advocates that the incorporation of zirconia crystals to ZLS composition increases strength, a previous study could not prove this effect, ${ }^{17}$ a result further endorsed in a study with Raman spectroscopy and X-ray diffraction. ${ }^{30}$ Despite similarities in composition, LD and ZLS present different slow crack growth coefficients (property that controls the time in service of brittle materials) and crack propagation patterns showed by fractographic analysis ${ }^{17}$, leading to the different fatigue strength values found in this study.

The PIC showed higher fatigue resistance than FC. The polymer network probably improved the performance of the material, and the incorporated crystals increased the resistance to fracture. The PIC also presents higher elastic modulus, resulting in higher damage tolerance ${ }^{31}$ when compared to FC. Both presented a low susceptibility to slow crack growth, ${ }^{17}$ making these materials interesting from a clinical longevity standpoint. In spite of the high fatigue strength observed in our study, Belli et al. ${ }^{30}$ stated that the crystalline spectrum of PIC resembles that of feldspathic ceramics, and that its inorganic phase is composed mainly of pure glass, with a very low fraction of crystalline reinforcement.

The fractography showed that all the fractures initiated at the side of the disk under tensile stress, opposite to load application site. Surface defects were the main origin of fractures. Due to the microstructure, the weaker materials (feldspathic and hybrid ceramics) presented rather rough surfaces and subtle cracked lines around the origins. ${ }^{32}$ 
As study limitations, it should be mentioned that the planar geometry (discs), the standardized sample preparations, and the loading protocols do not reproduce the clinical situation. However, our data can provide information about fatigue behavior of different materials. In addition, the fatigue tests were performed under water; there are reports showing a reduction in the flexural strength of ceramic materials in water compared to testing in a dry environment, due to corrosion of the ceramic by water molecules, leading cracks to grow. ${ }^{33,34}$ This aspect is directly associated with the clinical failures of ceramic restorations. ${ }^{35,36}$ Even though cyclic accelerated fatigue is considered an aggressive condition, Fraga et al., ${ }^{21}$ showed that fatigue tests could be conducted with up to $20 \mathrm{~Hz}$ without compromising fatigue data. In addition, specimen geometry (crowns, bridges) can modify stress and failure patterns, which was not evaluated

\section{References}

1. Kelly JR, Benetti P. Ceramic materials in dentistry: historical evolution and current practice. Aust Dent J. 2011 Jun;56(56 Suppl 1):84-96. https://doi.org/10.1111/j.1834-7819.2010.01299.x

2. Denry I, Kelly JR. Emerging ceramic-based materials for dentistry. J Dent Res. 2014 Dec;93(12):1235-42. https://doi.org/10.1177/0022034514553627

3. Gracis S, Thompson VP, Ferencz JL, Silva NR, Bonfante EA. A new classification system for all-ceramic and ceramiclike restorative materials. Int J Prosthodont. 2015 MayJun;28(3):227-35. https://doi.org/10.11607/iip.4244

4. Ramakrishnaiah R, Alkheraif AA, Divakar DD, Matinlinna JP, Vallittu PK. The effect of hydrofluoric acid etching duration on the surface micromorphology, roughness, and wettability of dental ceramics. Int J Mol Sci. 2016 May; 17(6):1-17. https://doi.org/10.3390/ijms17060822

5. Gehrt M, Wolfart S, Rafai N, Reich S, Edelhoff D. Clinical results of lithium-disilicate crowns after up to 9 years of service. Clin Oral Investig. 2013 Jan;17(1):275-84. https://doi.org/10.1007/s00784-012-0700-x

6. Pieger S, Salman A, Bidra AS. Clinical outcomes of lithium disilicate single crowns and partial fixed dental prostheses: a systematic review. J Prosthet Dent. 2014 Jul;112(1):22-30. https://doi.org/10.1016/i.prosdent.2014.01.005

7. Elsaka SE, Elnaghy AM. Mechanical properties of zirconia reinforced lithium silicate glassceramic. Dent Mater. 2016 Jul;32(7):908-14. https://doi.org/10.1016/j.dental.2016.03.013 in this study. ${ }^{37}$ Finally, brittle materials (such as ceramics) obtain sufficient strength when adhesively bonded, ${ }^{22,38}$ hence, the absence of adhesive bonds is another limitation of this study. Direct extrapolation of the present data should be done with caution, as the ceramic materials were exposed only to an axial load applied in the center of the specimens, disregarding all the complexities of the oral environment.

\section{Conclusion}

Within the limitations of this in vitro study, it was concluded that the highly translucent polycrystalline zirconia bears higher cyclic load before cracking/fracturing than the other tested materials. The magnitude of occlusal load should be considered when choosing the type of material for a monolithic restoration.
8. Scientific documentation, VITA, 2015

9. Chun EP, Anami LC, Bonfante EA, Bottino MA. Microstructural analysis and reliability of monolithic zirconia after simulated adjustment protocols. Dent Mater. 2017 Aug;33(8):934-43. https://doi.org/10.1016/i.dental.2017.04.024

10. Zhao K, Wei YR, Pan Y, Zhang XP, Swain MV, Guess PC. Influence of veneer and cyclic loading on failure behavior of lithium disilicate glass-ceramic molar crowns. Dent Mater. 2014 Feb;30(2):164-71. https://doi.org/10.1016/i.dental.2013.11.001

11. Kimmich M, Stappert CF. Intraoral treatment of veneering porcelain chipping of fixed dental restorations: a review and clinical application. J Am Dent Assoc. 2013 Jan;144(1):31-44. https://doi.org/10.14219/jada.archive.2013.0011

12. Joda T, Ferrari M, Brägger U. Monolithic implant-supported lithium disilicate (LS2) crowns in a complete digital workflow: A prospective clinical trial with a 2-year followup. Clin Implant Dent Relat Res. 2017 Jun;19(3):505-11. https://doi.org/10.1111/cid.12472

13. Rauch A, Reich S, Schierz O. Chair-side generated posterior monolithic lithium disilicate crowns: clinical survival after 6 years. Clin Oral Investig. 2017 Jul;21(6):2083-9. https://doi.org/10.1007/s00784-016-1998-6

14. Lohbaver U, Krämer N, Petschelt A, Frankenberger $R$. Correlation of in vitro fatigue data and in vivo clinical performance of a glassceramic material. Dent Mater. 2008 Jan;24(1):39-44. https://doi.org/10.1016/j.dental.2007.01.011 
- Fatigue strength of several dental ceramics indicated for CAD-CAM monolithic restorations

15. ISO 6872, 2008. Dentistry-Ceramic Materials, 3rd ed. International Organization for Standardization, Geneva 2008.

16. Pereira G, Amaral M, Cesar PF, Bottino MC, Kleverlaan CJ, Valandro LF. Effect of low-temperature aging on the mechanical behavior of ground Y-TZP. J Mech Behav Biomed Mater. 2015 May;45:183-92. https://doi.org/10.1016/i.jmbbm.2014.12.009

17. Ramos NC, Campos TM, Paz IS, Machado JP, Bottino MA, Cesar PF et al. Microstructure characterization and SCG of newly engineered dental ceramics. Dent Mater. 2016 Jul;32(7):870-8. https://doi.org/10.1016/j.dental.2016.03.018

18. Della Bona A, Corazza PH, Zhang Y. Characterization of a polymer-infiltrated ceramic-network material. Dent Mater. 2014 May;30(5):564-9. https://doi.org/10.1016/i.dental.2014.02.019

19. Borba M, de Araújo MD, de Lima E, Yoshimura HN, Cesar PF, Griggs JA et al. Flexural strength and failure modes of layered ceramic structures. Dent Mater. 2011 Dec;27(12):1259-66. https://doi.org/10.1016/i.dental.2011.09.008

20. Collins JA. Staircase or up-and-down methods: failure of materials in mechanical design. New York: John Wiley \& Sons; 1993. p. 383-90.

21. Fraga S, Pereira GK, Freitas M, Kleverlaan CJ, Valandro LF, May LG. Loading frequencies up to $20 \mathrm{~Hz}$ as an alternative to accelerate fatigue strength tests in a Y-TZP ceramic. J Mech Behav Biomed Mater. 2016 Aug;61:79-86. https://doi.org/10.1016/i.jmbbm.2016.01.008

22. Venturini AB, Prochnow C, May LG, Kleverlaan CJ, Valandro LF. Fatigue failure load of feldspathic ceramic crowns after hydrofluoric acid etching at different concentrations. J Prosthet Dent. 2018;119(2):278-85. https://doi.org/10.1016/i.prosdent.2017.03.021

23. Villefort RF, Amaral M, Pereira GK, Campos TM, Zhang Y, Bottino MA et al. Effects of two grading techniques of zirconia material on the fatigue limit of full-contour 3-unit fixed dental prostheses. Dent Mater. 2017 Apr;33(4):e155-64. https://doi.org/10.1016/i.dental.2016.12.010

24. Zucuni CP, Guilardi LF, Fraga S, May LG, Pereira GK, Valandro LF. CAD/CAM machining $V$ s pre-sintering inlab fabrication techniques of Y-TZP ceramic specimens: effects on their mechanical fatigue behavior. J Mech Behav Biomed Mater. 2017 Jul;71:201-8. https://doi.org/10.1016/i.jmbbm.2017.03.013

25. Johansson C, Kmet G, Rivera J, Larsson C, Vult Von Steyern P. Fracture strength of monolithic all-ceramic crowns made of high translucent yttrium oxide-stabilized zirconium dioxide compared to porcelain-veneered crowns and lithium disilicate crowns. Acta Odontol Scand. 2014 Feb;72(2):145-53. https://doi.org/10.3109/00016357.2013.822098
26. Baladhandayutham B, Lawson NC, Burgess JO. Fracture load of ceramic restorations after fatigue loading. J Prosthet Dent. 2015 Aug;114(2):266-71. https://doi.org/10.1016/i.prosdent.2015.03.006

27. Tinschert J, Zwez D, Marx R, Anusavice KJ. Structural reliability of alumina-, feldspar-, leucite-, mica- and zirconia-based ceramics. J Dent. 2000 Sep;28(7):529-35. https://doi.org/10.1016/S0300-5712(00)00030-0

28. Sulaiman TA, Abdulmajeed AA, Donovan TE, Ritter AV, Vallittu PK, Närhi TO et al. Optical properties and light irradiance of monolithic zirconia at variable thicknesses. Dent Mater. 2015 Oct;31(10):1180-7. https://doi.org/10.1016/i.dental.2015.06.016

29. Zhang Y. Making yttria-stabilized tetragonal zirconia translucent. Dent Mater. 2014 Oct;30(10):1195-203. https://doi.org/10.1016/j.dental.2014.08.375

30. Belli R, Wendler M, de Ligny D, Cicconi MR, Petschelt A, Peterlik $\mathrm{H}$ et al. Chairside CAD/CAM materials. Part 1: measurement of elastic constants and microstructural characterization. Dent Mater. 2017 Jan;33(1):84-98. https://doi.org/10.1016/j.dental.2016.10.009

31. Coldea A, Swain MV, Thiel N. In-vitro strength degradation of dental ceramics and novel PICN material by sharp indentation. J Mech Behav Biomed Mater. 2013 Oct;26:34-42. https://doi.org/10.1016/i.jmbbm.2013.05.004

32. Scherrer SS, Lohbaver U, Della Bona A, Vichi A, Tholey MJ, Kelly JR et al. ADM guidance-Ceramics: guidance to the use of fractography in failure analysis of brittle materials. Dent Mater. 2017 Jun;33(6):599-620. https://doi.org/10.1016/j.dental.2017.03.004

33. Zeng K, Odén A, Rowcliffe D. Flexure tests on dental ceramics. Int J Prosthodont. 1996 Sep-Oct;9(5):434-9.

34. De Aza AH, Chevalier J, Fantozzi G, Schehl M, Torrecillas R. Crack growth resistance of alumina, zirconia and zirconia toughened alumina ceramics for joint prostheses. Biomaterials. 2002 Feb;23(3):937-45. https://doi.org/10.1016/S0142-9612(01)00206-X

35. Chevalier J. What future for zirconia as a biomaterial? Biomaterials. 2006 Feb;27(4):535-43. https://doi.org/10.1016/i.biomaterials.2005.07.034

36. Hooi $P$, Addison $O$, Fleming GJ. Strength determination of brittle materials as curved monolithic structures. J Dent Res. 2014 Apr;93(4):412-6. https://doi.org/10.1177/0022034514523621

37. Kelly JR, Denry I. Stabilized zirconia as a structural ceramic: an overview. Dent Mater. 2008 Mar;24(3):289-98. https://doi.org/10.1016/i.dental.2007.05.005

38. May LG, Kelly JR, Bottino MA, Hill T. Effects of cement thickness and bonding on the failure loads of CAD/ CAM ceramic crowns: multi-physics FEA modeling and monotonic testing. Dent Mater. 2012 Aug;28(8):e99-109. https://doi.org/10.1016/i.dental.2012.04.033 